\title{
LUMINESCENCE OF Eu(III), Pr(III) AND Sm(III) IN CARBONATE-FLUOR-APATITE
}

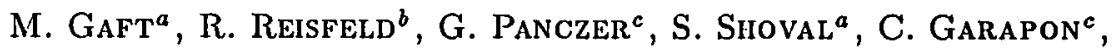 \\ G. BOULON ${ }^{c}$ AND W. STREK ${ }^{d}$ \\ ${ }^{a}$ The Open University, Physics and Geology Groups \\ 16 Klausner St., Tel-Aviv 61392, Israel \\ ${ }^{b}$ Enrique Berman Professor of Solar Energy, The Hebrew University \\ Department of Inorganic and Analytical Chemistry \\ 91904 Jerusalem, Israel \\ ${ }^{c}$ University Claude Bernard Lyon 1 \\ Physico-Chimie des Materiaux Luminescents, CNRS \\ 69622 Villeurbanne, France \\ ${ }^{d}$ Institute for Low Temperature and Structure Research, Polish Academy of Sciences \\ P.O. Box 937, 50-950 Wrocław, Poland
}

The purpose of this work was identification of luminescent lines occurring in natural carbonate-fluor-apatite (francolite) mineral. For identification of several rare earth ions occurring in natural francolite, the luminescence of rare earth ions was extensively studied in artificial mineral consisting of a pure francolite (not containing rare earth) of the composition $\mathrm{Ca}_{5}\left(\mathrm{PO}_{4}\right)_{3}(\mathrm{~F}, \mathrm{O}): \mathrm{Ca}_{5}\left(\mathrm{PO}_{4}\right)_{3} \mathrm{CO}_{3}$ activated with $\mathrm{Pr}, \mathrm{Eu}$ and $\mathrm{Sm}$ ions and then compared with the luminescence features observed in natural mineral.

PACS numbers: 78.55.IIx

\section{Introduction}

The mineral francolite (carbonate-fluor-apatite) $\mathrm{Ca}_{5}\left(\mathrm{PO}_{4}, \mathrm{CO}_{3}\right)_{3}(\mathrm{~F}, \mathrm{OH})$ occurs in vast deposits, and is utilized on a large scale allowing also the recovery of many by-products. The mineral is sometimes substantially enriched in rare earth elements making their extraction possible. The distiction between the various chemical forms of rare earth (RE) poses a fundamental problem. If they occur as an adsorbed or separate phase, selective extraction is possible. However, if they occur as structural substitute, they may be removed only by dissolving or melting the apatite host, thus requiring high energy uses [1].

The luminescence of the traces of $\mathrm{RE}$ ions have been studied extensively in natural and artificial fluorapatite $\mathrm{Ca}_{5}\left(\mathrm{PO}_{4}\right)_{3}(\mathrm{~F}, \mathrm{OH})$. So far, no evidence from luminescence research exists about the exact location and valence of RE in francolite. It is the purpose of this work to examine the following questions: what is the valence of the RE present and where they are located. 


\section{Experimental}

\subsection{Samples}

The sedimentary apatite in this study included approximately 100 samples from the phosphorate of Israel and around the world (Russia, Estonia, USA, Jordan, Finland, Marocco, Albania). All samples were checked by infrared spectroscopy in order to exclude those with the impurities of foreign minerals (mainly calcite) which are able to serve as host matrix for luminescence centers.

\subsection{Methods}

To achieve our goals we have utilized the technique of time-delayed spectroscopy. This method permits spectral detection of elements having relatively weak luminescence with long decay times on the background of the strong emission of organic matter with extremely short decay (less than $20 \mathrm{~ns}$ ).

The luminescence spectra were examined by UV laser excitation $(308 \mathrm{~nm})$ which delivers pulses of 10 nanoseconds duration and $0.1 \mathrm{~cm}^{-1}$ spectral width. The pulse energy was maintained at about $80 \mathrm{~mJ}$. The luminescence observed at $90^{\circ}$ was analyzed with a IIilger and Watt 1 monochromator with a grating of 1200 grooves $/ \mathrm{mm}$ blazed at $500 \mathrm{~mm}$. The luminescence in the range of $400-900 \mathrm{~nm}$ was detected by a fast response AsGa photomultiplier (RCA 31084) and the signal was fed into a Canberra multichannel analyzer for the lifetime data. The experimental setup was controlled by a PC computer. The lifetime analysis of the decay curves was accomplished with an Origin computer program which allows to achieve the best fit for experimental curve with several exponents and to assess their relative contributions.

Ileating the samples up to $900^{\circ} \mathrm{C}$ causes significant changes in the luminescence. The thermal treatment was carried out in air, in the temperature interval of $300-900^{\circ} \mathrm{C}$. The sample was held at each temperature for one hour and then cooled down to room temperature in the oven.

For the correct interpretation of the luminescent lines, artificial activation by different RE was accomplished by heating the mixtures of natural francolite with corresponding oxides $\left(1 \%\right.$ of $\mathrm{Eu}_{2} \mathrm{O}_{3}$ and $5 \%$ of $\mathrm{Sm}_{2} \mathrm{O}_{3}$ and $\left.\mathrm{Pr}_{2} \mathrm{O}_{3}\right)$ at $900^{\circ} \mathrm{C}$ in air. Artificial oxyapatite $\mathrm{Ca}_{5}\left(\mathrm{PO}_{4}\right)_{3} \mathrm{OII}$ was also activated at the same conditions.

\section{Experimental results}

Luminescence of RE is well known in natural fluorapatite $[2,3]$ but it was not detected in all natural carbonate-fluor-apatites under investigations. After heating the francolite samples in air at $800-900^{\circ} \mathrm{C}$, a set of very intensive and narrow lines appears with the strongest maxima at 595, 619, 626, 634 and $646 \mathrm{~nm}$ (Fig. 1a). At liquid nitrogen temperature new lines appear at 603, 615, 651, 653 and $656 \mathrm{~nm}$ (Fig. 1b).

In order to distinguish some lines which belong to different sites, fluorescence decay was measured (Fig. 2). At room temperature the lifetimes of the 634 and $646 \mathrm{~nm}$ lines are practically the same with the main components of 0.023 and $0.7 \mathrm{~ms}$. The line at $619 \mathrm{~nm}$ is characterized by much shorter decay time with 
two main components of 0.002 and $0.09 \mathrm{~ms}$. At nitrogen temperature the line at $650 \mathrm{~nm}$ has two main components of 0.07 and $0.09 \mathrm{~ms}$. The other lines are weak and the measured values are uncertain.
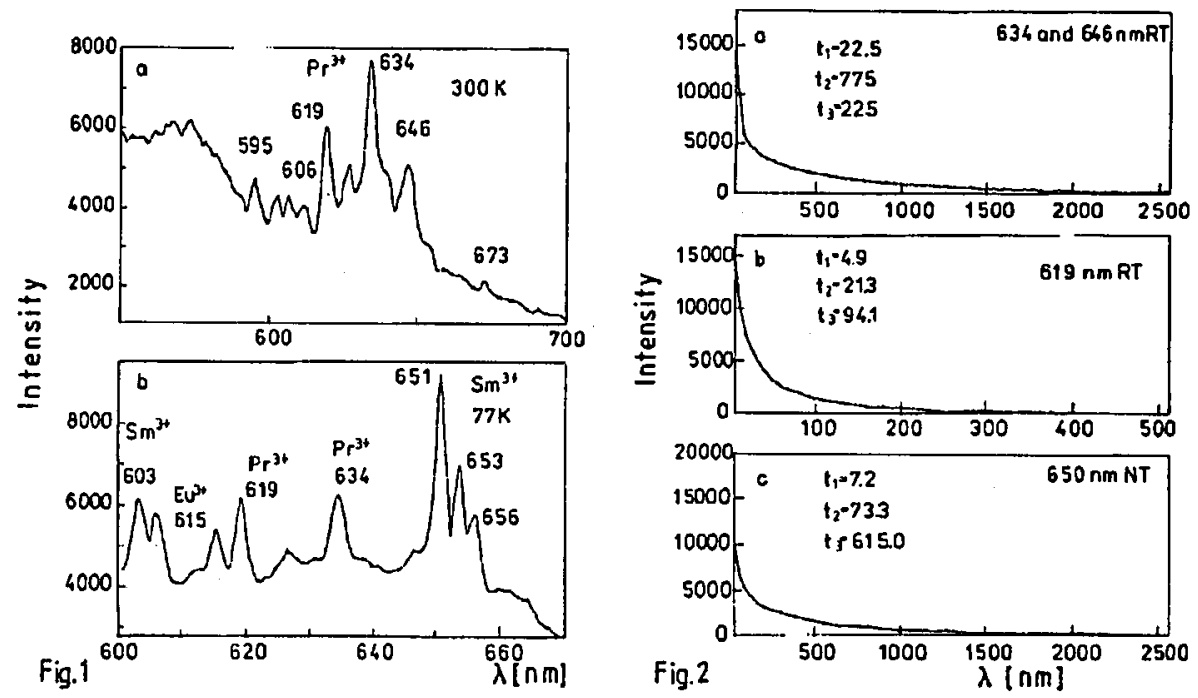

Fig. 1. Luminescence of $\mathrm{RE}$ in natural francolite after heating at $900^{\circ} \mathrm{C}$.

Fig. 2. Fluorescence decay of different lines in carbonate-fluor-apatite.
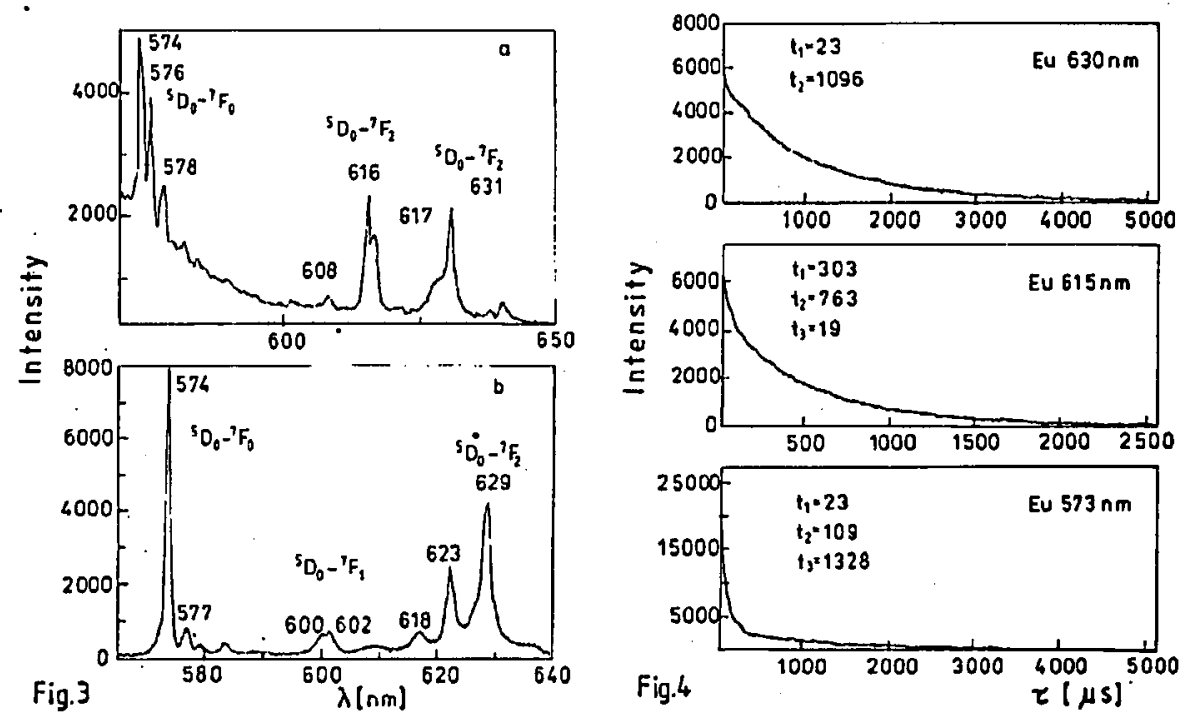

Fig. 3. Luminescence spectrum of $\mathrm{Eu}^{3+}$ in activated francolite (a) and oxyapatite (b) Fig. 4. Fluoroscençe decay of different lines in carbonate-fluor-apatite activated by $\mathrm{Eu}^{3+}$. 

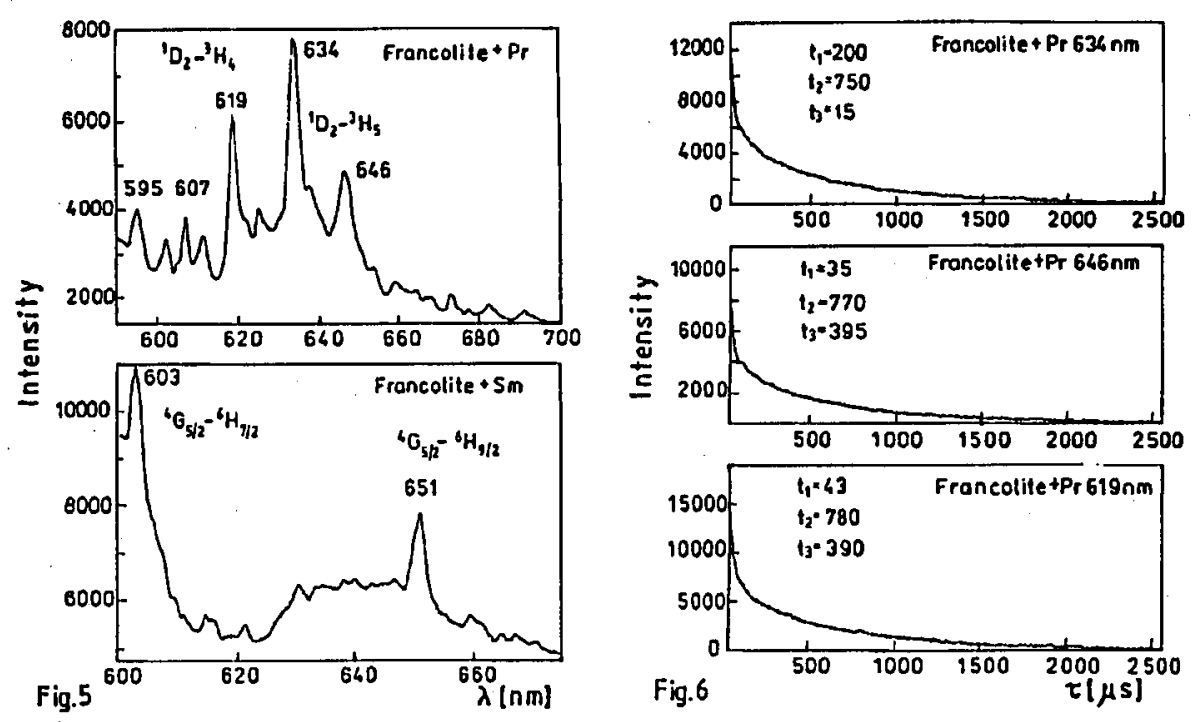

Fig. 5. Luminescence spectra of carbonate-fluor-apatite activated by $\mathrm{Pr}^{3+}$ and $\mathrm{Sm}^{3+}$. Fig. 6. Fluorescence decay of different lines in the carbonate-fluor-apatite activated by $\operatorname{Pr}^{3+}$.

In the luminescence spectrum of natural francolite activated by $\mathrm{Eu}^{3+}$ three groups of lines are observed (Fig. 3a). The first group has distinctive sharp lines at 574,576 and $578 \mathrm{~nm}$, while the second and the third grups are centered at 616 and $631 \mathrm{~nm}$. In the luminescence spectrum of artificial oxyapatite activated by $\mathrm{Eu}^{3+}$ only two intensive groups are present at 575 and $630 \mathrm{~nm}$, while the line at $617 \mathrm{~nm}$ is very weak (Fig. 3b). The lines at $574 \mathrm{~nm}$ and $630 \mathrm{~nm}$ in both cases have similar decay times of 1.1-1.3 ms (the short decay at $574 \mathrm{~nm}$ is connected with uranyl luminescence which is extremely strong in francolite after heating at $\left.800^{\circ} \mathrm{C}[5]\right)$, while the line at $616 \mathrm{~nm}$ in francolite is characterized by shorter decay of 0.75 ms (Fig. 4).

Luminescence spectrum of natural francolite activated by $\mathrm{Pr}^{3+}$ consists of a number of groups of lines in the orange and red end of the spectrum (Fig. 5a). For the weak lines the values are uncertain, but for the strong ones the main decay components are rather similar (0.75-0.78 ms) (Fig. 6).

In luminescence spectrum of natural francolite activated by $\mathrm{Sm}^{3+}$ two groups of lines appear at 600 and $650 \mathrm{~nm}$ (Fig. 5b). The line at $650 \mathrm{~nm}$ has very strong long components of $2.8 \mathrm{~ms}$, while such components are not detected for the line at $603 \mathrm{~nm}$. These values are doubtful because of the strong background luminescence.

\section{Discussion}

\subsection{Crystallochemical features}

The composition of the ideal fluorapatite corresponds to formula $\mathrm{Ca}_{10}\left(\mathrm{PO}_{4}\right)_{6} \mathrm{~F}_{2}$. There are 42 atoms in the unit cell and the parameters of fluo- 


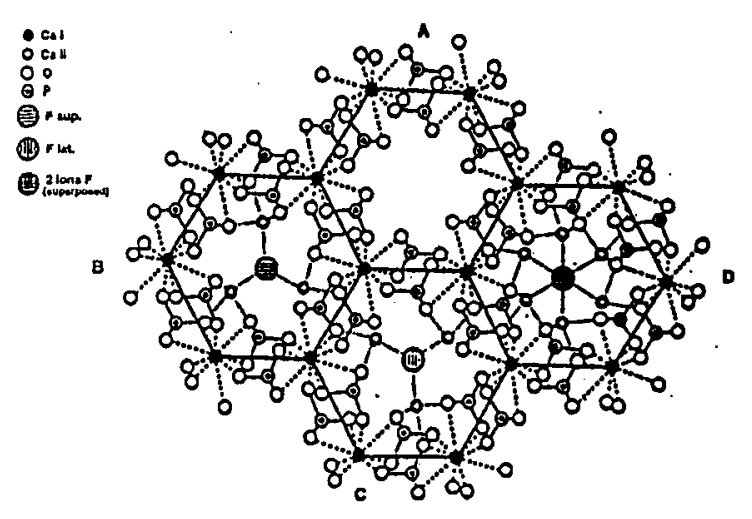

Fig. 7. The structure of $\mathrm{Ca}_{10}\left(\mathrm{PO}_{4}\right)_{6} \mathrm{~F}_{2}$.

roapatite are $a=9.364 \AA, c=6.879 \AA$. The structure of apatite is hexagonal with the symmetry group $P_{3} / \mathrm{m}$. There are three types of polyhedrons in the apatite structure: $\mathrm{Ca}(\mathrm{I}), \mathrm{Ca}(\mathrm{II})$ and $\mathrm{PO}_{4}^{2-}$. Isolated orthophosphate groups are situated along the second order axes between the columns of $\mathrm{Ca}(\mathrm{I})$ and $\mathrm{Ca}$ (II). Isolated orthophosphate groups are situated in the center of the $\mathrm{Ca}$ (II) column along the hexagonal axis. 'There are two nonequivalent sites of the $\mathrm{Ca}^{2+}$ ions: $40 \%$ are associated with $\mathrm{Ca}$ (I) and $60 \%$ with $\mathrm{Ca}$ (II). The point symmetry of the $\mathrm{Ca}$ (I) site is $C_{3}$ with each $C_{a}$ having six oxygen nearest neighbors which form a distorted triangular prism around the $\mathrm{Ca}^{2+}$ ion. The $\mathrm{Ca}$ (II) site has $C_{s}$ symmetry with the $\mathrm{Ca}^{2+}$ ions sitting at the corners of equilateral triangles with $\mathrm{F}^{-}$ion as the center (Fig. 7). The role of the carbonate ions in apatite is one of the most discussed problems in the crystillochemistry of apatite. It is proved by now that carbonate ions enter into the apatite structure and two nonequivalent positions were proposed: in place of the orthophosphate ions and on the hexagonal axis [2].

The presence of two cation sites suggests that upon activation with $\mathrm{RE}$ ions at least two types of activator centers can be formed. Moreover, because in such a heterovalent activation the need arises for excess charge compensation, which can be eflected in different ways, the number of center types can even be larger.

\subsection{Luminescence spectra of $R E$}

\subsubsection{Eu(III)}

Trivalent europium ions are widely used as luminescent probes in the investigation of the crystallochemical structure of the activator centers. Particularly informative is the study of the transition between the two non-degenerate terms ${ }^{7} F_{0}$ and ${ }^{5} D_{0}$. The presence of several lines in this region can be caused by the existence of several types of activator centers, while the relative intensity can serve as a characteristic of the local symmetry [6-12].

The luminescence of $\mathrm{Eu}^{3+}$ in carbonate-fluor-apatite has the following features: 
1. The most intense lines near $575 \mathrm{~nm}$ may be unambiguously interpreted as a pure electronic transition ${ }^{5} D_{0} \rightarrow{ }^{7} F_{0}$. Its strong relative intensity and unusually high position are similar to those detected in fluorapatite and oxyapatite $[4,13]$.

2. The ${ }^{5} D_{0} \rightarrow{ }^{7} F_{0}$ region of the $\mathrm{Eu}^{3+}$. strong lines at 574,576 and $578 \mathrm{~nm}$ suggests the multiplicity of activator sites which is more pronounced compared with oxyapatile activilted by $\mathrm{Eu}^{3+}$ at the same conditions (Fig. 3). The ${ }^{5} D_{0} \rightarrow{ }^{7} F_{0}$ transition is sufliciently large only in cases where the site symmetry allows an electric dipole process. The symmetries allowing such a process are $C_{s}, C_{v}$ and $C_{n v}$ [S]. Thius, it may be concluded that such centers are formed by replacement of low-synumetry $\mathrm{Ca}$ (II) sites with activator ions, while the different lines are connected with dilferent ways of excessive charge compensation.

3. The lines at $631 \mathrm{~nm}$ have the similar decay time with the line at $574 \mathrm{~nm}$ (1.1 and $1.3 \mathrm{~ms}$, correspondingly). It is possible to suppose that they belong to the same activator site and are connected with the ${ }^{5} D_{0} \rightarrow{ }^{6} F_{0}$ transition.

4. The lines at $616 \mathrm{~mm}$ are much stronger compared to oxyapatite activated by $\mathrm{Eu}^{3+}$ at the sime conditions (Fig. 3). Their spectral position is also typical of ${ }^{5} D_{0} \rightarrow{ }^{6} F_{0}$ transition. The large magnitude of this hypersensitive transition and the shorter decay lime of $0.75 \mathrm{~ms}$ indicate that we deal with another activator site with larger asymmetric part of the crystal field. The relocation of carbonate ions during healing from the position of orthophosphate groups of the hexagonal axes may be responsil)le for the symmetry lowering of the $\mathrm{Ca}(\mathrm{II})$ position [2].

\subsection{2. $\operatorname{Pr}(I I I)$}

The lumincscence of $\mathrm{Pr}^{3+}$ in carbonate-fluor-apatite has the following features:

1. The bluc luminescence which is connected with ${ }^{4} P_{0} \rightarrow{ }^{3} H_{4}$ transition and is very intensive in fluorapatite [4] is not detected.

2. Two sequences of lines may be detected: $595,607,619,634 \mathrm{~nm}$ and 602 , 611,625 and $640 \mathrm{~mm}$. It is possible to suppose that they represent two activator sites willt slightly different, symmetries. The similar decay times of the lines indicate that the corresponding transitions are comnected with the same excited level ${ }^{3} P_{0}$ or ${ }^{1} D_{2}$. A detailed study of this topic will be presented later, but the relatively long decay time is in the fav vor of the ${ }^{1} D_{2}$ level [14]. The luminescence quenching from the ${ }^{3} P_{0}$ level in the carbonate-fluor-apatite may be due to a transfer of excitation energy to the vibrations of the lattice. For $R E$ when considerable quenching occurs the energy dillcrence between the electronic levels approximately equals the energy of four phonons [15]. The energy difference between the ${ }^{3} P_{0}$ and the lower ${ }^{1} D_{2}$ levels is approximately $3580 \mathrm{~cm}^{-1}$ which is practically equal to the four phonons of the $v_{2}$ vibration of the carbonate groups $\left(870-880 \mathrm{~cm}^{-1}\right.$ [2]).

\subsection{3. $\mathrm{Sm}(I I I)$}

The luminescence of $\mathrm{Sm}^{3+}$ in carbonate-fluor-apatite is very similar to those in fluorapatite [1] with two distinct lines connected with ${ }^{4} G_{5 / 2} \rightarrow{ }^{6} I_{7 / 2}(603 \mathrm{~nm})$ transitions. The possible reason is that the radiating term is separated from the nearest lower level $T F_{11 / 2}$ by an energy interval of $7500 \mathrm{~cm}^{-1}$ which is too large 
compared to the encrgy of phonons of carbonate groups to accomplish an effective nonradiative relaxation of excited levels.

It is inlercsting to note that $\mathrm{Sm}^{3+}$ luminescence in fluorapatite activated in the reduced conditions is different [1]. The possible reason is the formation of the centers by replacement of low-symmetry and high-symmetry calcium sites, but this problem needs futher clarification.

\subsection{Natural luminescence}

The experiments with artificial activation of carbonate-fluor-apatite allow to interpret the lumincscence lines found in natural samples. According to their spectral position, the lines at $603,651,653$ and $656 \mathrm{~nm}$ may be ascribed to $\mathrm{Sm}^{3+}$, the lines at 606,619 and $646 \mathrm{~nm}$ to the $\mathrm{Pr}^{3+}$, the line at $615 \mathrm{~nm}$ to $\mathrm{Eu}^{3+}$ and the line at $634 \mathrm{~nm}$ is connected with $\mathrm{Pr}^{3+}$ and $\mathrm{Eu}^{3+}$ ions.

Decay times of the lines at 634 and $646 \mathrm{~nm}$ in natural samples and activated by $\mathrm{Pr}^{3+}$ are also close $(0.7-0.78 \mathrm{~ms})$ which confirms their connection. The decay time of the line at $619 \mathrm{~nm}$ is much shorter in natural sample in comparison with activated onc. This problem needs further investigation.

Iuminescence of RE is well known in natural fluorapatite $[1,16]$ but in carbonate--[luor-an)atite it is observed only after heating. Two possibilities exist to explain this clifficrence. It is possible that in carbonate-fluor-apatite the luminescence is quenched by the components with high-energy phonons. The latter may be represented by water and organic matter which are present in carbonate-fluor- apatite in much larger quantities as compared to fluorapatite. They are removed after heating and luminescence becomes visible. Another possibility is that carbonatefluor-apatite accomodates RE in concentrated adsorbed form, which quenches the fluorescence by concentration interaction $[3,15]$. As a result of high temperature heating, hermal diflision of RE in lattice takes place with resulting luminescence.

\section{Acknowledgment}

The authors are very grateful to Professor C.K. Jørgensen for illuminating discussions.

\section{R.eferences}

[1] A. Portuov, B. Gorobets, Dokl. Akad. Nauk SSSR 184, 110 (1969).

[2] R. Kinubovets, Rev. Chem. Eng. 9, 161 (1993).

[3] A. Marufiu, Speclroscopy, Luminescence and Radiation Centers in Minerals, Springer Verlitg, Berlin 1979.

[4] A. Morozov, L. Morozova, A. Trefilov, Opt. Spectrosc. 29, 590 (1970).

[5] C.K. Jorgensen, R. Reisfeld, Struct. Bond. 50, 121 (1982).

[6] R. Reis[eld, S'truct. Bond. 30, 65 (1976).

[7] R. Reisleld, J. Less-Common Met. 112, 9 (1985).

[8] R. Reisleld, iı: Spectroscopy of Solid State Laser-Type Materials, Ed. B. DiBartolo, Plenum, New York 1987, p. 343.

[9] R. Reisfeld, C.K. Jørgensen, in: Handbook on the Physics and Chemistry of Rare Earths, Eds. K.A. Gschneider, L. Eyring, Vol. 9, North-Holland, Amsterdam 1987, Ch. 58, p. 1. 
[10] R. Reis[eld, Inorg. Chim. Acta 140, 345 (1987).

[11] R. Reisleld, NATO Adv. Study Inst. Ser. B, Phys. 249, 397 (1991).

[12] R. Reisleld, C.K. Jørgensen, Acta Phys. Pol. A 84, 1011 (1993).

[13] B. Pirou, D. Fahmi, J. Dexpert-Glys, A. Taitou, J.L. Lacout, J. Lumin. 39, 97 (1987).

[14] R. Reisleld, C.K. Jørgensen, Lasers and Excited States of Rare Earths, Springer-Verling, Berlin 1977.

[15] R. Reisleld, Struc. Bond. 13, 53 (1973).

[16] A. Tarashclian, Luminescence of Minerals, Naukova Dumka, Kiev 1978 (in Russian). 